\title{
EFFECTS OF COMBINED NUTRIENT AND WATER STRESS ON THE GROWTH OF HOPEA ODORATA ROXB. AND MIMUSOPS ELENGI LINN. SEEDLINGS
}

\author{
by Siti Rubiah Zainudin', Kamis Awang², and Ahmad Husni bin Mohd. Hanif ${ }^{3}$
}

\begin{abstract}
The growth of Hopea odorata and Mimusops elengi seedlings under drought and various fertilization rates under nursery conditions was investigated. Both $\mathrm{H}$. odorata and $M$. elengi seedlings responded differently to fertilizer application and drought. Application of slow-release fertilizer (Best Tab, 20:10; 5 NPK) at 30 and 50 g promoted greater height growth for $H$. odorata and M. elengi seedlings, respectively. M. elengi seedlings were able to tolerate high fertilizer application (50 g), but the resulting form (small trunk diameter and excessive height) was not suitable for urban planting. Growth of H. odorata seedlings was greatly promoted through application of $30 \mathrm{~g}$ of fertilizer under wellwatered conditions, resulting in a much more balanced growth in terms of shoot and root ratio, which is vital for plants growing in the harsh urban environment where competition for water and nutrients is usually intense.

Key Words. Hopea odorata; Mimusops elengi; urban environment; drought; fertilization; plant growth.
\end{abstract}

Soil conditions and tree nutrition are limiting factors to tree growth in urban areas. Urban sites are often subjected to soil removal or disturbance during road construction, resulting in loss of organic matter and nutrients (Craul 1992). Plant moisture and the onset of plant water stress caused by soil water deficits are generally recognized as the principal limiting factors controlling the growth of urban trees (Kozlowski 1986; Clark and Kjelgren 1990; Day 1994; Tognetti et al. 1995). Apart from drought, plants are subjected to soil compaction, a serious problem in urban areas (Craul 1992). Thus, urban soil conditions can be difficult for root growth (Watson 1998) because nutrients are often limiting under conditions of soil compaction and water stress. Plant growth is often retarded because the ability of plant roots to absorb maximum nutrients is impaired.

The impact of drought on ornamental plants is most serious after the plants are transplanted in the landscape (Craul 1992). Urban soils have poor chemical quality and lack capacity to retain water. An evaluation of water economy of street trees in New York City, U.S., found that tree water deficits occurred less frequently than presumed and that water deficits were more closely linked to high evaporative demand than to limited soil moisture (Whitlow et al. 1992). Therefore, additional information on the water required by trees to remain healthy, particularly information linked to aerial and an edaphic planting site characteristic, is needed.

This study was undertaken to determine the growth performance of Hopea odorata and Mimusops elengi seedlings under drought conditions and various fertilization rates during nursery production and determine whether drought reduces the negative impact over fertilization on seedlings.

\section{MATERIALS AND METHODS Potting Medium and Seedlings}

A Tropeptic haplorthox soil series was used in the experiment, and the soil was mixed thoroughly in an automated mixer. It was later sieved to remove stones and other unwanted materials before filling $4 \mathrm{~kg}$ into polythene pots measuring $30 \mathrm{~cm}$ height and $24 \mathrm{~cm}$ diameter with a volume of $452 \mathrm{~cm}^{3}$ of soil. The seeds of Hopea odorata and Mimusops elengi were collected from the Forest Research Institute Malaysia (FRIM) and the Universiti Putra Malaysia arboreta. The seeds were germinated in a sand bed. After germination, the seedlings were transplanted into polythene bags with a potting mixture of 7:3:2 soil, sand, and peat. Uniform seedlings (in terms of height) were selected and transplanted one to a pot. At the age of 6 months old, seedlings of both species were used for the experiment at different periods, $H$. odorata first, then 3 months later M. elengi.

\section{Experimental Design and Treatments}

The experiment was a $6 \times 2$ factorial design arranged in randomized complete block with each treatment replicated six times, for a total of 288 polybags. Tables 1 and 2 give the treatment combinations and the levels of various nutrients present in the treatment combinations. Slow-release fertilizer (Best Tab, 20:10; 5 NPK) was applied once at the beginning of the experiment and was placed $10 \mathrm{~cm}$ below the surface in tablet form (NPK 20-10-5). The watering treatments were (I) no stress (seedlings were kept well watered at field capacity $\geq-0.3 \mathrm{MPa}$ ); and (2) water stress (water was withheld until the soil water potential was $\geq-1.5$ $\mathrm{MPa}$ and then rewatered to field capacity). 
Table 1. Treatment combinations and levels of fertilizer applied.

\begin{tabular}{ll}
\hline Treatment & Amount added (g/pot) of NPK (20-10-5) \\
\hline F0W0 & No fertilizer and well-watered at field capacity $\geq-0.3 \mathrm{MPa}$ \\
F0W1 & No fertilizer and water-stressed at soil water potential $\geq-1.5 \mathrm{MPa}$ \\
F1W0 & $10 \mathrm{~g}$ of fertilizer and well-watered at field capacity $\geq-0.3 \mathrm{MPa}$ \\
F1W1 & $10 \mathrm{~g}$ of fertilizer and water-stressed at soil water potential $\geq-1.5 \mathrm{MPa}$ \\
F2W0 & $20 \mathrm{~g}$ of fertilizer and well-watered at field capacity $\geq-0.3 \mathrm{MPa}$ \\
F2W1 & $20 \mathrm{~g}$ of fertilizer and water-stressed at soil water potential $\geq-1.5 \mathrm{MPa}$ \\
F3W0 & $30 \mathrm{~g}$ of fertilizer and well-watered at field capacity $\geq-0.3 \mathrm{MPa}$ \\
F3W1 & $30 \mathrm{~g}$ of fertilizer and water-stressed at soil water potential $\geq-1.5 \mathrm{MPa}$ \\
F4W0 & $40 \mathrm{~g}$ of fertilizer and well-watered at field capacity $\geq-0.3 \mathrm{MPa}$ \\
F4W1 & $40 \mathrm{~g}$ of fertilizer and water-stressed at soil water potential $\geq-1.5 \mathrm{MPa}$ \\
F5W0 & $50 \mathrm{~g}$ of fertilizer and well-watered at field capacity $\geq-0.3 \mathrm{MPa}$ \\
F5W1 & $50 \mathrm{~g}$ of fertilizer and water-stressed at soil water potential $\geq-1.5 \mathrm{MPa}$ \\
\hline
\end{tabular}

Table 2. Levels of nutrients applied (grams per pot)

\begin{tabular}{lllllll}
\hline & & \multicolumn{5}{c}{ Treatment } \\
\cline { 3 - 7 } Commercial fertilizer & Element & $\mathrm{F} 1$ & $\mathrm{~F} 2$ & $\mathrm{~F} 3$ & $\mathrm{~F} 4$ & $\mathrm{~F} 5$ \\
\hline Best Tabs (20-10-5) & $\mathrm{N}$ & 2.1 & 4.2 & 6.3 & 8.4 & 10.5 \\
& $\mathrm{P}_{2} \mathrm{O}_{5}$ & 1.05 & 2.1 & 3.15 & 4.2 & 5.25 \\
& $\mathrm{~K}_{2} \mathrm{O}$ & 0.525 & 1.05 & 1.575 & 2.10 & 2.625 \\
& $\mathrm{Ca}$ & 0.158 & 0.315 & 0.473 & 0.63 & 0.788 \\
& $\mathrm{Mg}$ & 0.053 & 0.105 & 0.158 & 0.21 & 0.263 \\
& $\mathrm{~S}$ & 0.263 & 0.525 & 0.788 & 1.05 & 1.313 \\
& $\mathrm{~B}$ & 0.002 & 0.004 & 0.006 & 0.008 & 0.10 \\
& $\mathrm{Cu}$ & 0.011 & 0.021 & 0.032 & 0.042 & 0.053 \\
& $\mathrm{Fe}$ & 0.079 & 0.158 & 0.237 & 0.316 & 0.395 \\
& $\mathrm{Mn}$ & 0.027 & 0.053 & 0.080 & 0.106 & 0.133 \\
& $\mathrm{Zn}$ & 0.027 & 0.053 & 0.080 & 0.106 & 0.159 \\
\hline
\end{tabular}

\section{Growth Measurements}

Height and diameter of the seedlings were measured every 3 months for 12 months. At the end of 12 months, the seedlings were harvested. Dry-matter production was obtained by carefully uprooting the seedlings from the pot. The roots were thoroughly washed and each plant separated into leaves, stems, and roots. The plant parts were oven-dried at $80^{\circ} \mathrm{C}$ (for up to $72 \mathrm{~h}$ ) to a constant weight, and dry weight was recorded. Total leaf area was measured with a leaf area meter. Root:shoot ratio was calculated as the ratio of the dry weight of root to the dry weight of the shoots and leaves. Root lengths were measured from the collar to the root tip with a meter ruler.

\section{Data Analysis}

The data were subjected to two-way analysis of variance (ANOVA) to determine the significance of the various factors and their interactions. Treatment mean were separated using Duncan's New Multiple Range Test, at $\alpha=$ 0.05 level of significance.

\section{RESULTS AND DISCUSSION Analysis of Variance}

There was a significant $(P \leq 0.0001)$ interaction between fertilizer rate and soil moisture (Table 3) of both species after 12 months.

\section{Above Ground \\ Hopea odorata seedlings receiving $30 \mathrm{~g}$ of fertilizer under well-watered conditions (F3W0) had the highest height and diameter throughout the 12-month period, and application of more than $30 \mathrm{~g}$ of fertilizer did not increase seedling growth (Table 4). Seedling growth was lower at all levels of fertilization under water-stressed conditions due to the limited amount of water uptake by the plant roots affecting overall growth of the seedlings. In contrast to $H$. odorata seedlings, fertilizer application at $50 \mathrm{~g}$ under well-watered conditions greatly promoted height growth of M. elengi seedlings compared to those under water-stressed conditions (Table 4). The result shows that high nitrogen fertilizer can cause accelerated top growth, creating an imbalance between the crown and root system of M. elengi seedlings. The lowest height recorded was under unfertilized and water-stressed condi- tions (FOW1), indicating that height} growth of M. elengi seedlings was greatly depressed under conditions of water stress and nutrient deficiency. Like $H$. odorata seedlings, the optimal diameter growth of M. elengi seedlings can be achieved by applying $30 \mathrm{~g}$ of fertilizer under well-watered conditions (Table 4).

\section{Below Ground}

Hopea odorata root length decreased with increasing levels of fertilizer for both watering regimes; the effects were more pronounced under water-stress treatments (Figure la). Unfertilized and water-stressed (FOW1) seedlings recorded the highest root length, indicating that root growth was promoted under limited water-stress treatments. Plants treated with $50 \mathrm{~g}$ of fertilizer under water-stressed conditions (F5W1) recorded the lowest root length, indicating that excess fertilizer can reduce root formation. Root length of M. elengi seedlings decreased with increasing levels of fertilizer for both watering regimes after 12 months (Figure 1b). The lowest root length was recorded for unfertilized plants under well-watered conditions (FOWO), indicating that low nutrient availability, coupled with well-watered 
Table 3. Results of ANOVAs on height and diameter of Hopea odorata and Mimusops elengi seedlings after 12 months.

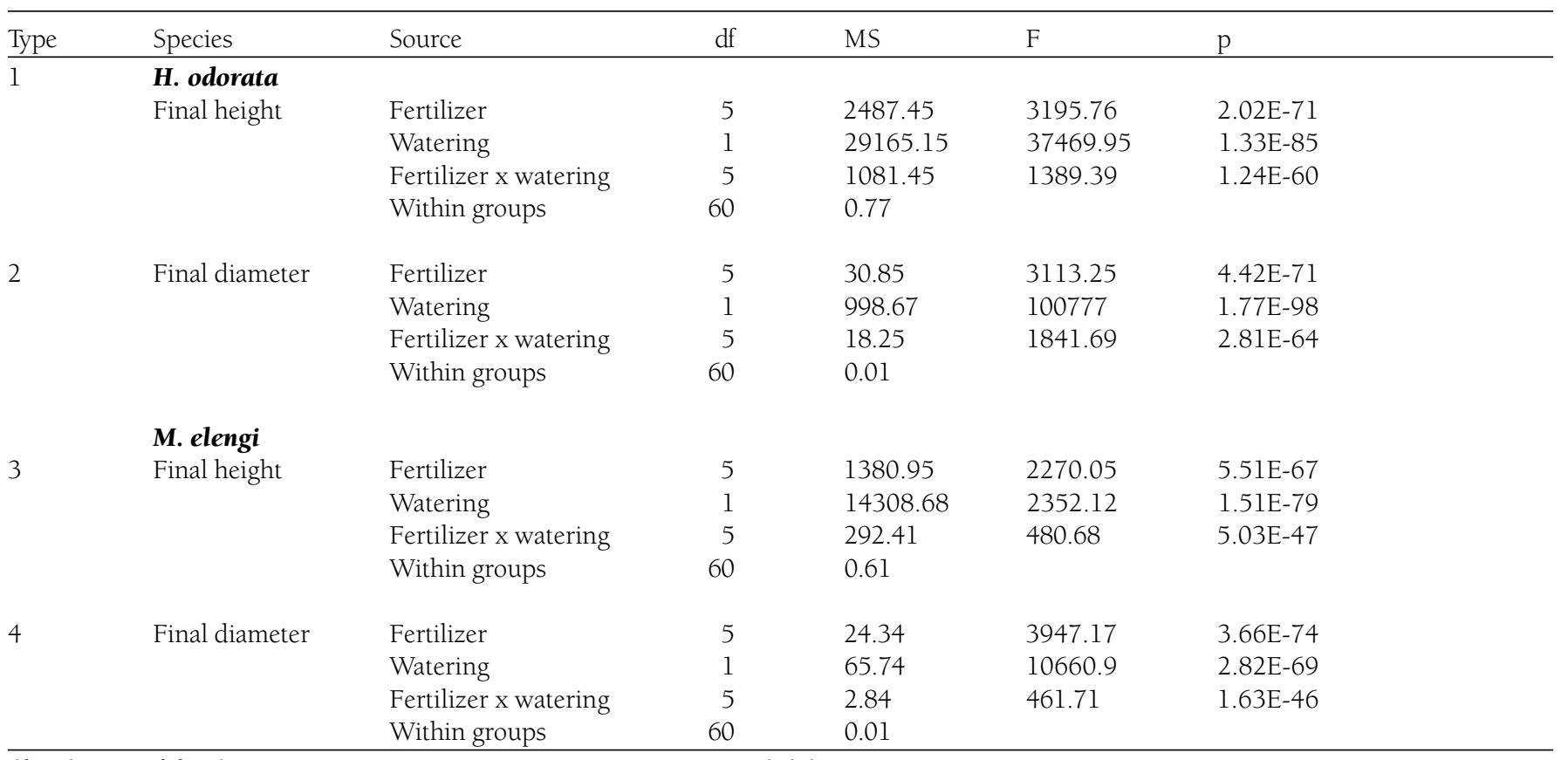

$\mathrm{df}=$ degrees of freedom; $\mathrm{MS}=$ mean square $\mathrm{F}=$ variance ratio $; \mathrm{p}=$ probability .

conditions, depressed root growth for M. elengi seedlings. Root:shoot ratio of H. odorata and M. elengi seedlings on a weight basis after 12 months was relatively higher under water-stressed conditions compared to well-watered plants at all levels of fertilization (Figures 2a, b). This finding suggests that under water-stressed conditions, plants shifted relatively more assimilates to the roots.

The results of the present study showed that application of slow-release fertilizer (Best Tab, 20:10; 5 NPK) up to $50 \mathrm{~g}$ increased height growth for both $H$. odorata and M. elengi seedlings. The results are consistent with those obtained from other studies on slow-release fertilization: Osmocote 18:6:12 NPK with Pseudoacacia menziesii (Castellano et al. 1985) and Liriodendron tulipifera (Hunt and Nicholls 1986); and Best Tab 20-10-5 NPK with Azadirachta excelsa (Ong 1998). The best seedling quality growth in terms of height, diameter, and other growth parameters of $\mathrm{H}$. odorata seedlings was greatly enhanced by the application of $30 \mathrm{~g}$ of fertilizer under well-watered conditions (F3W0). Application of greater than $30 \mathrm{~g}$ of fertilizer did not increase the growth performance, probably because the amount of nutrient applied was too high, resulting in luxury consumption of nutrients in the treated seedlings. M. elengi seedlings responded differently-application of up to $50 \mathrm{~g}$ of fertilizer under well-watered conditions (F5W0) promoted only height growth but resulted in smaller-diameter plants.
Table 4. Mean values of height and diameter of Hopea odorata and Mimusops elengi after 12 months of treatments.

\begin{tabular}{llll}
\hline Species & Treatment & Height & Diameter \\
\hline Hopea odorata & F0W0 & $50.20 \mathrm{e}^{\mathrm{x}}$ & $7.70 \mathrm{e}$ \\
& F1W0 & $65.50 \mathrm{~d}$ & $8.08 \mathrm{~d}$ \\
& F2W0 & $94.48 \mathrm{~b}$ & $12.20 \mathrm{c}$ \\
& F3W0 & $103.33 \mathrm{a}$ & $14.03 \mathrm{a}$ \\
& F4W0 & $89.67 \mathrm{c}$ & $12.89 \mathrm{~b}$ \\
& F5W0 & $48.00 \mathrm{f}$ & $8.17 \mathrm{~d}$ \\
& FOW1 & $31.50 \mathrm{j}$ & $2.70 \mathrm{~g}$ \\
& F1W1 & $34.33 \mathrm{i}$ & $2.78 \mathrm{~g}$ \\
& F2W1 & $38.50 \mathrm{~h}$ & $3.29 \mathrm{f}$ \\
& F3W1 & $42.83 \mathrm{~g}$ & $3.45 \mathrm{f}$ \\
& F4W1 & $35.00 \mathrm{i}$ & $3.45 \mathrm{f}$ \\
F5W1 & $27.50 \mathrm{k}$ & $2.70 \mathrm{~g}$ \\
FoW0 & $35.16 \mathrm{f}$ & $4.71 \mathrm{~g}$ \\
F1W0 & $40.83 \mathrm{e}$ & $5.98 \mathrm{e}$ \\
F2W0 & $43.16 \mathrm{~d}$ & $7.51 \mathrm{c}$ \\
& F3W0 & $61.17 \mathrm{c}$ & $8.50 \mathrm{a}$ \\
F4W0 & $67.00 \mathrm{~b}$ & $7.70 \mathrm{~b}$ \\
F5W0 & $72.83 \mathrm{a}$ & $4.53 \mathrm{~h}$ \\
F0W1 & $18.16 \mathrm{k}$ & $3.33 \mathrm{j}$ \\
F1W1 & $23.50 \mathrm{j}$ & $3.36 \mathrm{j}$ \\
F2W1 & $30.50 \mathrm{~h}$ & $4.73 \mathrm{~g}$ \\
F3W1 & $32.16 \mathrm{~g}$ & $5.08 \mathrm{f}$ \\
F4W1 & $27.83 \mathrm{i}$ & $6.31 \mathrm{~d}$ \\
F5W1 & $18.83 \mathrm{k}$ & $3.65 \mathrm{i}$ \\
\hline
\end{tabular}

zSymbols are the same as for Table 1.

${ }^{x}$ Means with the same letter are not significantly different at $P<0.05$ as determined by Duncan's Multiple Range Test. 


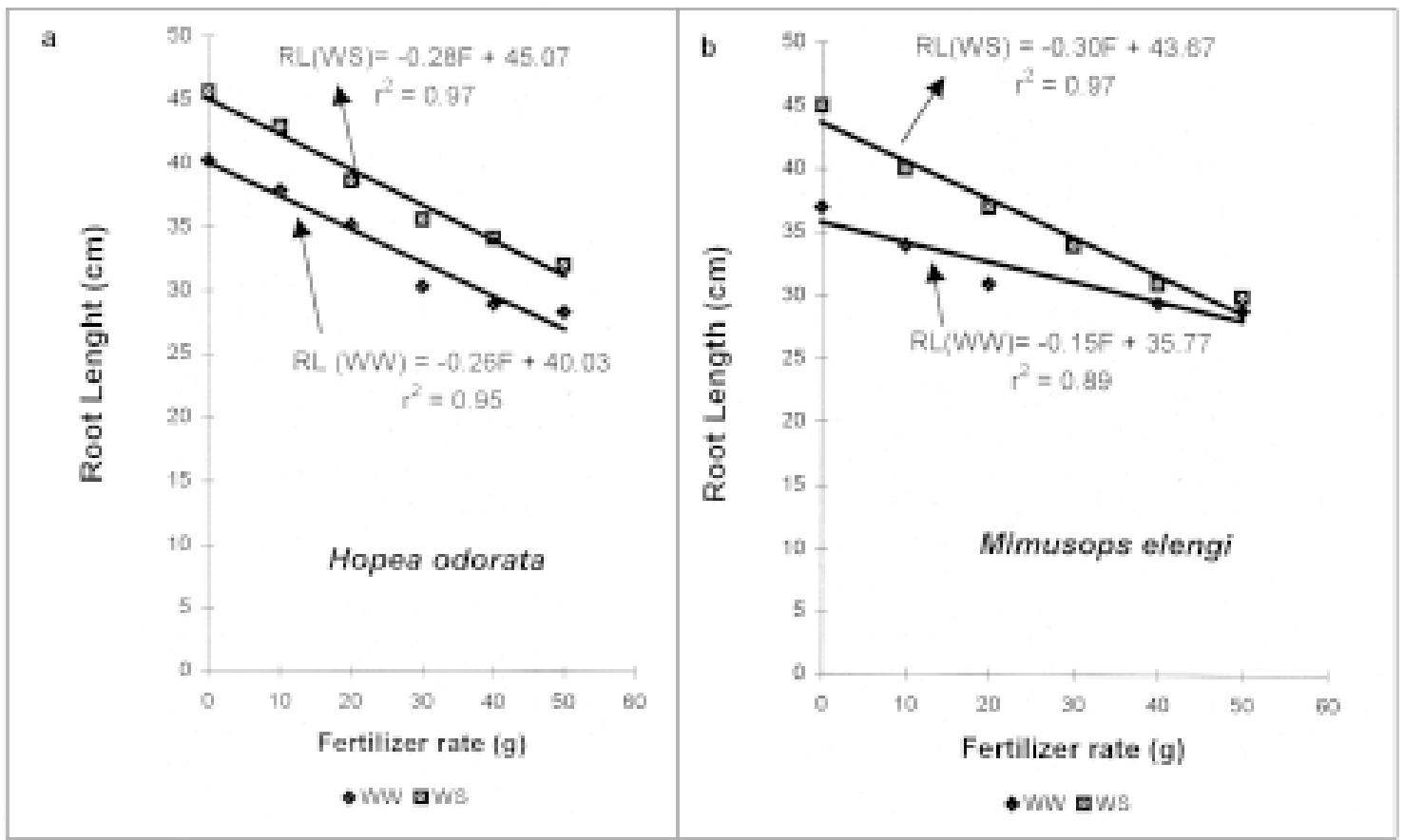

Figure 1. The relationship between root length of $H$. odorata and $M$. elengi seedlings under two watering regimens as affected by fertilizer treatments after 12 months. Each point represents mean of six measurements. WW = well-watered plants; $W S=$ water-stressed plants; $R L=$ root length; $\mathbf{F}$ = fertilizer rate $(\mathrm{g})$.

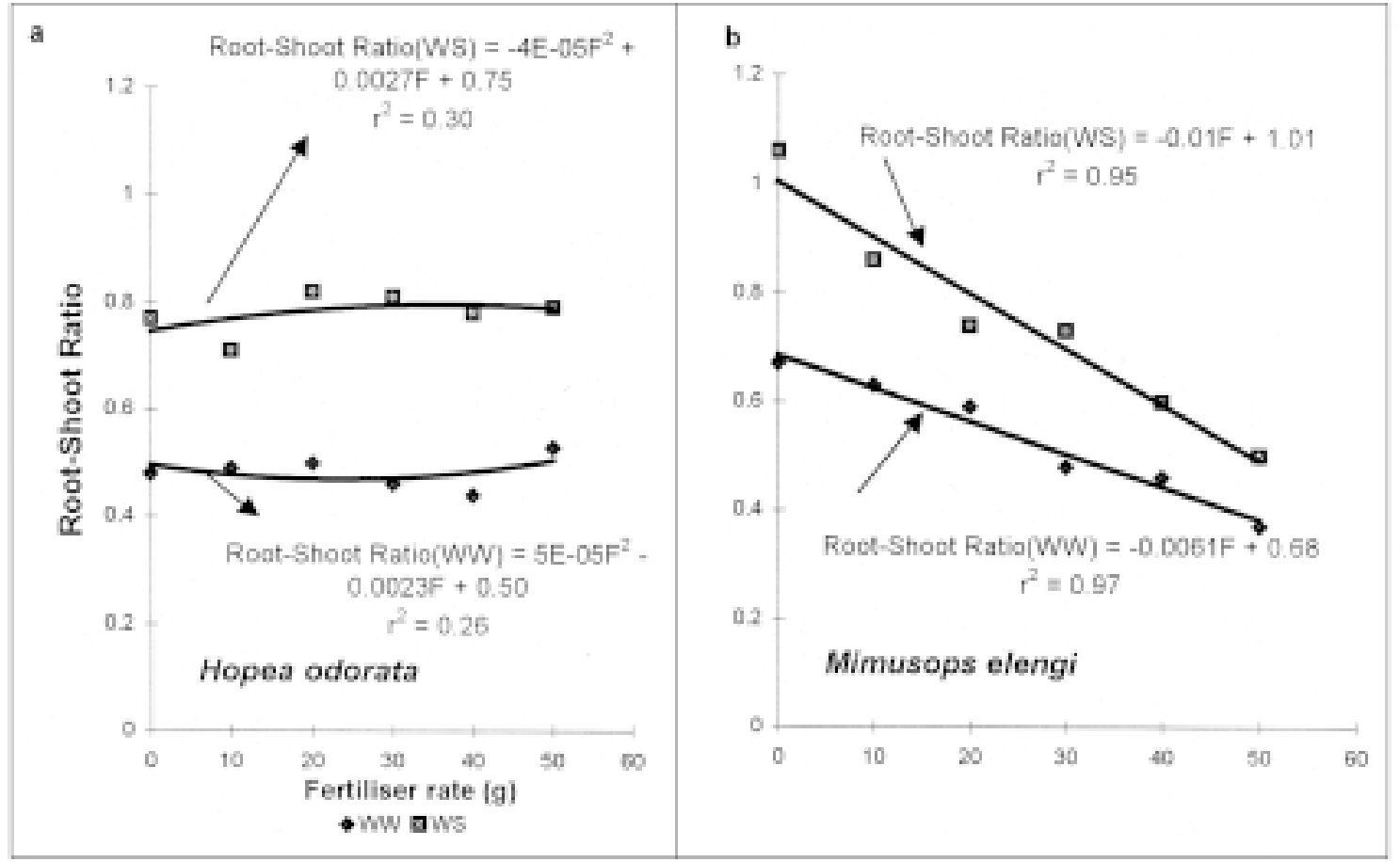

Figure 2. Root:shoot ratios of $H$. odorata and $M$. elengi seedlings under two watering regimens as affected by fertilizer treatments after 12 months. Each point represents mean of six measurements. WW = well-watered plants; WS = water-stressed plants; $R \mathbf{L}=$ root length; $\mathbf{F}=$ fertilizer rate (g). 


\section{CONCLUSIONS}

Hopea odorata and Mimusops elengi seedlings responded differently to fertilizer application and water stress. M. elengi seedlings were able to tolerate high fertilizer application (50 $\mathrm{g}$ ), resulting in enhanced height but thinner diameter. This characteristic make M. elengi less suitable for urban planting. Growth of H. odorata seedlings was greatly promoted through application of $30 \mathrm{~g}$ under well-watered conditions (F3WO), resulting in a much more balanced growth in terms of shoot:root ratio, which is vital for plants growing in the harsh urban environment.

\section{LITERATURE CITED}

Castellano, M.A., J.M. Trappe, and R. Molina. 1985. Inoculation of container-grown Douglas-fir seedlings with basidiospores of Rhizopogon vinicolor and R. colossus: Effects of fertility and spore application rate. Can. J. For. Res. 15:10-13.

Clark, J.R., and R.K. Kjelgren. 1990. Water as a limiting factor in the development of urban tree plants. J. Arboric. 16(8):203-208.

Craul, P.J. 1992. Urban Soil in Landscape Design. John Wiley and Sons. Inc., New York, NY. 323 pp.

Day, S.D. 1994. A review of the effects of soil compaction on amelioration treatment on landscape trees. J. Aboric. 20(1):9-015.

Hunt, R., and A. Nicholls. 1986. Stress and the coarse control of growth and root-shoot partitioning in herbaceous plants. Oikos 47:149-158.

Kozlowski, T.T. 1986. Soil aeration, flooding and tree growth. J. Arboric. 11(3):85-94.

Ong, K.H. 1995. Respond of sentang (Azadirachta excelsa (Jack) Jacobs) to nutrient stress. B.C.(For). Thesis, Universiti Pertanian Malaysia, Serdang.

Tognetti, R., J.D. Johnson, and M. Michelozzi. 1995. The response of European beech (Fagus sylvatica L.) seedlings from two Italian populations to drought and recovery. Trees 9:348-354.

Watson, G.W. 1998. Tree planting and establishment. Metrop. Tree Improv. Alli. (METRIA) 9:1-5.

Whitlow, T.H., N.L. Bassuk, and D.L. Reicher. 1992. A 3-year study of water relations of urban stress trees. J. Appl.

Ecol. 29: 436-450.

Acknowledgments. We thank Ong Kian Huat and Abdul Latib Senin for the technical help. Thanks are also extended to Assoc. Prof. Dr. Lim Meng Tsai for helpful suggestions, which greatly improved the manuscript. This work was part of a PhD project and was financed through IRPA and

Universiti Putra Malaysia.
${ }^{1 *}$ Institute of Biodiversity and Environmental Conservation (IBEC)

Universiti Malaysia Sarawak

94300 Kota Samarahan

Sarawak, Malaysia

${ }^{2,3}$ Faculty of Forestry

Universiti Putra Malaysia

43400 UPM Serdang

Selangor, Malaysia

*Corresponding author.

Résumé. La croissance en pépinière de semis d'Hopea odorata et de Mimusops elengi en condition de sécheresse et sous divers taux de fertilisation a été étudiée. Les semis de $H$. odorata et de M. elengi ont répondu différemment aux applications de fertilisants et à la sécheresse. L'application d'engrais à libération lente (Best TAb, 20:10, 5 NPK) à 30 et $50 \mathrm{~g}$ produisait une croissance en hauteur plus forte pour les semis de H. odorata et M. elengi. Les semis de M. elengi étaient capable de tolérer une application élevée d'engrais $(50 \mathrm{~g})$, mais la forme résultante (faible diamètre du tronc et hauteur excessive) n'était pas appropriée pour la plantation en milieu urbain. La croissance de H. odorata était fortement accrue grâce à une application de $30 \mathrm{~g}$ d'engrais sous des condition de bonne irrigation (F3W0), ce qui résultait en une croissance mieux balancée en terme de ratio pousses/ racines, un aspect vital pour les végétaux qui doivent croîtrent dans un environnement urbain difficile où la compétition pour l'eau et les éléments minéraux est généralement intense.

Resumen. Se investigó el crecimiento de brinzales de Hopea odorata y Mimusops elengi con tasas de riego y fertilización bajo condiciones de vivero. Tanto H. odorata como M. elengi respondieron en forma diferente a las aplicaciones de fertilizante y riego. Las aplicaciones de fertilizantes de disolución lenta (Best Tab, 20:10; 5 NPK) a 30

y $50 \mathrm{~g}$, produjeron mayor crecimiento en altura para los brinzales de H. odorata y M. Elengi, respectivamente. Los brinzales de M. elengi toleraron la aplicación alta de fertilizante $(50 \mathrm{~g})$, pero la forma resultante (diámetro pequeño del tronco y excesiva altura) no es deseable para plantaciones urbanas. El crecimiento de H. odorata fue mayormente promovido por la aplicación de $30 \mathrm{~g}$ de fertilizante bajo condiciones de riego apropiado (F3W0), resultando un mejor balance en crecimiento en términos de la relación raíz-tallo, lo cual es vital para el crecimiento de las plantas que crecen en condiciones urbanas críticas, donde la competencia por agua y minerales es usualmente intensa. 